\title{
Degradation and Moisture Absorption Study of Potato-starch Linear Low Density Polyethylene Blend
}

\author{
M.K.Yakubu, M.B. Musa and J.Mukaila
}

Department of Textile Science \& Technology, A.B.U-Zaria, Nigeria

\begin{abstract}
Composite of linear low density polyethylene (LLDPE) and potato-starch was produced and subjected to degradation studies with the agencies of enzymes, exposure to weather and immersion in water. Enzymatic hydrolysis degraded the matrix to an extent greater than $40 \%$ loss in strength and about 20\% loss in elongation-at-break within just 10 days. These deteriorations correlated with the decrease in weight. Immersion in water indicated increased uptakes with starch content which also corresponded with decrease in tensile strength and elongation-at-break with time of immersion. Exposure to weather completely reduced the composites to easily crushable masses the extent of which was also related to starch content. Micrographs of the tested samples showed that the weak points are the starch sections which after being eaten up by microorganisms or swollen up by moisture lend the matrix more amenable to further degradation.
\end{abstract}

INTRODUCTION: Attention of environmentalists in the recent years has focused on synthetic thermoplastics. They continue to litter the environment and persistently refuse natural degradation processes, as a result causing solid waste disposal problems, reduction of soil fertility and general untidiness of the planet (Arvanitoyannis et al., 1998). Research has been active in the search for alternatives; three areas have been earmarked. The first emphasizing synthetic polymers with groups susceptible to biodegradation (Pierre, et al., ,1987), the second approach is the use of biopolymers such as PHA (polyhydroxy alkanoates), PHB(polyhydroxy butyrate), PLA(polylactic acid), PHV(polyhydroxy valerate) (Holmens, et al.,1984). The third method is blending of some of the culprit plastics with biodegradable fillers (Shogren, 1989; Bastioli, 1995). The second option is by far the best green-wise; biopolymers are completely biodegradable, they however suffer from economics due to their high cost of production (Leaversuch, 2002).

More thrust is paid to blending of synthetic polymers with macromolecules such as starch, chitin and chitosan etc(Van Soest and Kortleve, 1999; Salmoral, et al., 2000; Park et al., 2001). Starch is widely considered a choice filler for this purpose; it is biodegradable, relatively cheap, non toxic and available in many forms(Lim, et al.,1992; Suvorova, et al.,2000). Starch films have very low permeability making them useful in food packaging. When starch is used in blends with non-biodegradable polymers it increases surface for microbial activity on the matrix(Koenig and Huang, 1995). It is also used as filler with biopolymers where economics is the main objective(Otey and Doane, 1984; Kotnis, et al.,1995). The present work is aimed at studying the biodegradability of indigenous potato starch filler on LLDPE.

\section{MATERIALS AND METHODS}

Determination of Tensile Properties: Tensile measurements of samples were carried out on a stelometer in triplicates according to ASTM D638. The results are shown in Figs. 1, 5 and 6.

Water Absorption: The weighed samples were submerged in water using sinkers in accordance with ASTM D570. Percentage moisture uptake $\left(\% \mathrm{M}_{\mathrm{t}}\right)$ was calculated accordingly. The result is indicated in Fig.3.

Enzymatic Tests: Enzymatic testing was carried our according to the method of Yoon $e t$ al. (1996). The samples were placed in a buffered biolase solution. The buffer solution was prepared by adding $4.5 \mathrm{~cm}^{3}$ of $0.2 \mathrm{M}$ acetic acid to $45.2 \mathrm{~cm}^{3}$ of $0.2 \mathrm{M}$ sodium acetate solution in $100 \mathrm{~cm}^{3}$ of solution. A control was prepared containing the samples in the buffer solution only. The sample's $\mathrm{pH}$ in the buffer and enzyme solutions were 6.8 and 9.4 respectively and kept at $37^{\circ} \mathrm{C}$ in an isolated box. Samples were taken out every five days 
for 30 days and washed thoroughly before conditioning in an oven at $50^{\circ} \mathrm{C}$ for 24 hours. Each sample was then weighed. The result is indicated in Figure 1

Natural Weathering: The samples were placed on a roof top and protected from wind and rain by placing a weight on the clamp end. They were turned over every day so that both surfaces were equally exposed to sunlight. Care was taken to prevent the samples from lying on each other. The average monthly temperature was $32^{\circ} \mathrm{C}$ while the average monthly relative humidity was $75 \%$.

\section{RESULT AND DISCUSSION}

Enzymatic Hydrolysis: Fig.1 shows the percentage reduction in tensile strength, elongation-at-break and weight with time for a $35 \mathrm{wt} \%$ starch in the composite after immersion in biolase solution for 25 days. The tensile strength, elongation-at-break and weight all decrease with time of immersion. The biodegradation pattern of the composite suggests that microbes consume starch and create pores in the materials, leading to increase in the surface area of LLDPE matrix and providing more susceptible groups for its biodegradation. This is indicated by the correlation of the mechanical properties with weight loss. Similar observation was made with PE/starch blends(Thakore, et al., 1999), and between LDPE/starch ester blends where weight loss due to removal of the starch component was positively correlated with the loss of mechanical properties. Biodegradation occasioned by burial procedure of $\mathrm{PE} / \mathrm{starch}$ blends was followed by gradual decrease in weight. This observation was explained by the consumption of starch from the matrix by microbes, SEM micrographs proved the theory. The micrographs shown in Fig.2 (i) and (ii) indicated bigger lesions in (i) which could be as a result of swelling of the starch and partial dissolutions. The starch granules are very visible in the only buffer- sucked samples shown in Fig.2(ii).

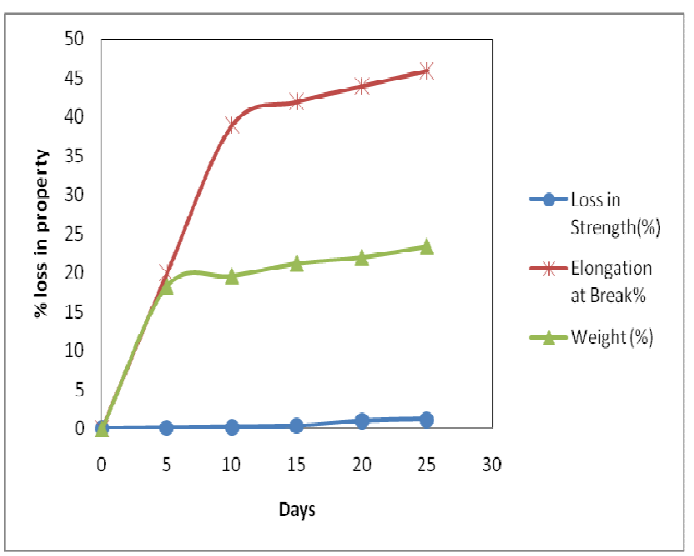

Figure1: Percentage reduction in properties of potato starch $35 \mathrm{wt} \%$ ) LLDPE composite with time of enzymatic treatment
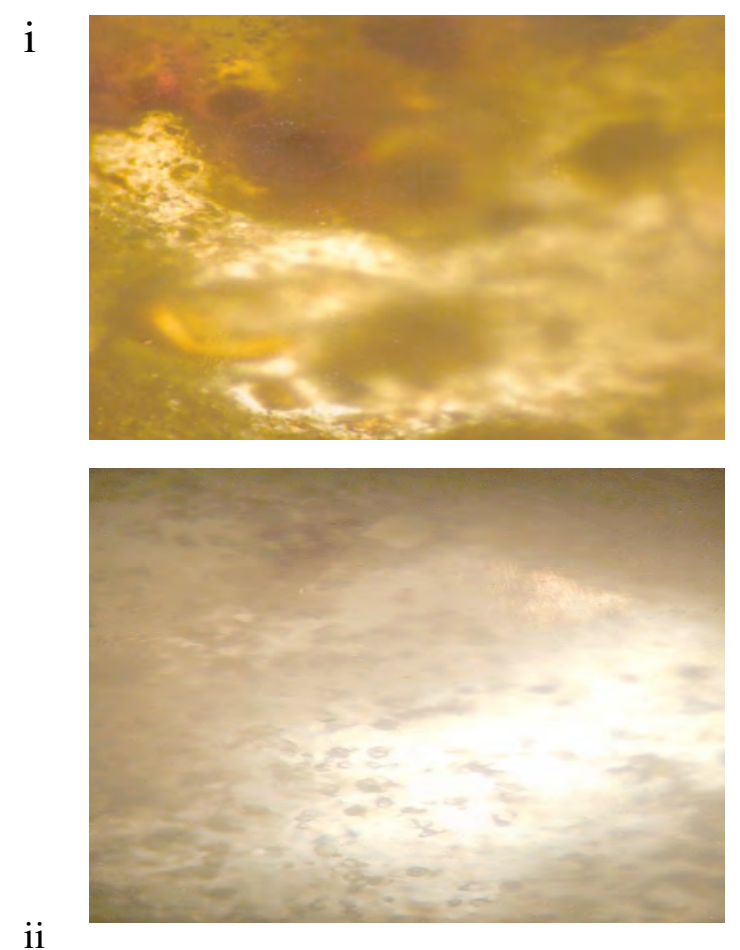

Figure2: Micrographs of the surface of potato starch (35 wt\%) - LLDPE Composite after (i) treatment with enzyme solution for 5 days and (ii) immersion in buffer solution for 5 days

Natural Weathering: The test was carried out during the period rain was most intense. The samples lost all their mechanical attributes and became very brittle. Fig. 3 is a micrograph of the sample containing $35 \mathrm{wt} \%$ starch after 3 months exposure. Large cracks appeared on the surface of the matrix exposing the 
embedded starch granules which easily gave in to combined biodegradation and photolysis.

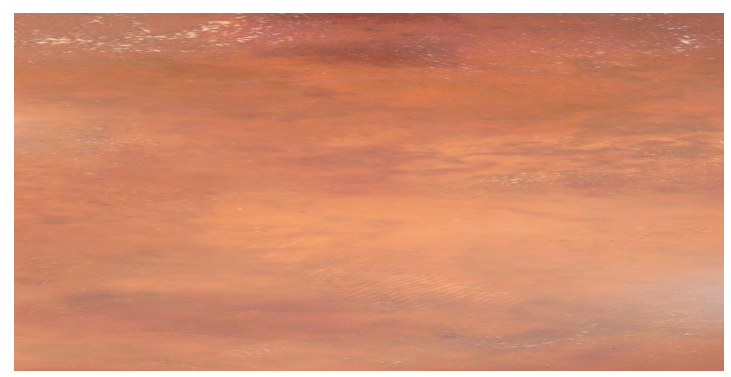

Figure3:Micrograph of the surface of potato starch (35 wt \%) - LLPDE composite after 3 months of natural weathering.

Water Absorption: Fig.4 gives the variation in moisture uptake with time of immersion and starch concentrations. As expected, moisture uptake increased with immersion time and starch concentration. Moisture is absorbed by starch/LLDPE composites through the starch particles. The rate of absorption of the moisture decreased with time of immersion, this was attributed to the changes in the concentration gradient across the two materials. Initial water molecules adsorbed to starch particles are strongly bonded to the hydroxyl groups as in a hydrate. When all of the available hydroxyl groups are used up, further water absorbed is held loosely (Willet, 1994). The increase of moisture uptake with increase in starch content has been reported earlier (Otey , 1987). Although, the composites were kept completely immersed in water for 30 days, they did not equilibrate. This also agrees with literature findings that starch/PE composites take months to equilibrate even when completely immersed in water (Otey, 1987).

Figs. 5 and 6 show plots of tensile strength and elongation-at-break against time of immersion, it is seen that tensile strength and elongationat-break decreased with time of immersion. This is due to the presence of moisture at the LLDPE/starch interface, which weakens the already weak interfacial adhesion. The longer the immersion time, the greater is the loss in tensile properties. Micrograph of the composite containing $35 \mathrm{wt} \%$ starch shows a rough surface full of holes (Fig. 7). The holes could be due to the removal of starch particles because of moisture, resulting in the granules swelling up, increasing in size and being forced out of the hole. Starch /LLDPE films were reported to expand by about $2 \%$ when aged at $100 \%$ relative humidity for 9 months.

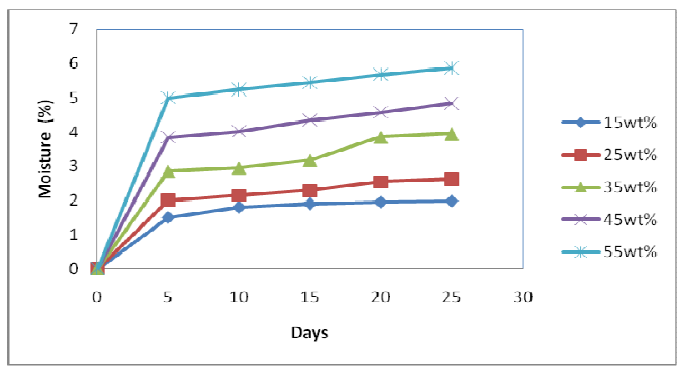

Figure 4: Variation in moisture uptake of potato starch - LLDPE composite with time of immersion

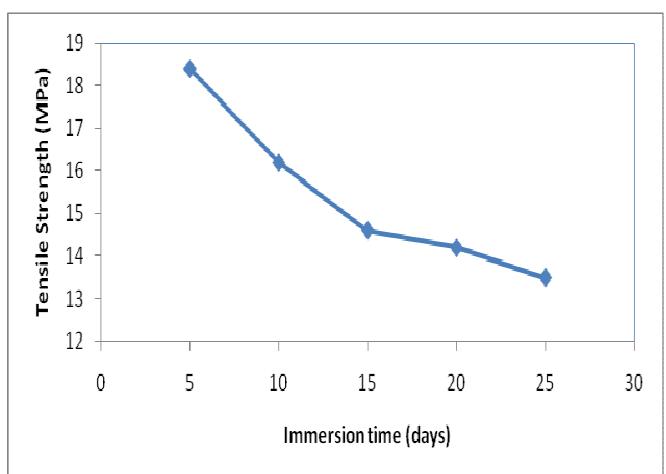

Figure 5: The effect of moisture uptake on the tensile strength of potato $\operatorname{starch}(35 \mathrm{wt} \%)-$ LLDPE composite

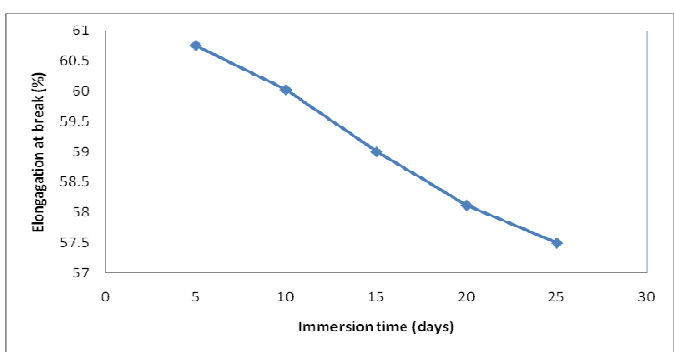

Figure 6: $\quad$ Effect of Moisture uptake on the elongation-at-break of potato $\operatorname{starch}(35 \mathrm{wt} \%)$ - LLDPE composite

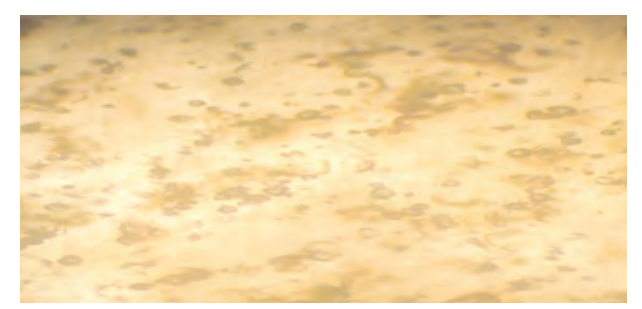

Figure 7: Micrograph of the surface of potato starch $(35 \mathrm{wt} \%)$ - LLPDE composite after immersion in water for 30 days 


\section{REFERENCES}

Arvanitoyannis, I.; Biliaderis, C. G.; Ogawa, H.; Kawasaki, N. (1998), Biodegradable films made from low-density polyethylene (LDPE), rice starch and potato starch for food packaging applications: Part 1 Carbohydr Polym, 36,87

Bastioli, C. (1995).In Degradable Polymers, Principles and Applications, 1 st ed.; Scott, G., Gilead, D., Eds.; Chapman \& Hall: London,; p 112.

Holmens, P. A.; Collins, S. H.; Wright, L. F. (1984).U.S. Pat. 4477 654,

katz, I.R.J.C. Derkesen, Z. Phys. Chem. 150A (1930) 100.

Koenig, M. F., and S. J. Huang. (1995). Biodegradable blends and composites of polycaprolactone and starch derivatives. Polymer 36:1877-1882.

Kotnis, M. A.; O'Brien, G. S.; Wellett, J. L. (1995).Processing and mechanical properties of biodegradable Poly(hydroxybutyrate-co-valerate)-starch compositions Environ Polym Degrad, 3, 97.

Leaversuch, R. (2002). Biodegradable polyesters; Packaging goes green. Plastics Technology.48(9): 66-73.

Lim, S. T.; Jane, J. L.; Rajagopalan, S.; and Seib, P. A. (1992). Effect of starch granule size on physical properties of starch-filled polyethylene film. Biotechnol. Prog.8(1):51-57

Otey, H. F.; Doane, M. W. (1984).In Starch: Chemistry and Technology,2nd ed.; Whistler, R. L., Bemiller, J. M., Paschall, E. F., Eds.; Academic Press: New York,; p 389.

Otey, F.H. R.P. Westhoff, W.M. Doane(1987). Ind. Eng. Chem. Res. 26 1659

Park, S.Y., Lee, B.I., Jung, S.T., Park, J.H. (2001). Biopolymer composite films based on kcarrageenan and chitosan. Materials Research Bulletin. 36: 511-519.
Pierre, T. S.; Chiellini, E. J. (1987). Review : Biodegradability of Synthetic Polymers for Medical and Pharmaceutical Applications: Part 3-Pendent Group Hydrolysis and GeneralConclusions.Journal of Bioactive and Compatible Polymers,; vol. 2: pp. $238-257$

Salmoral, E.M., Gonzalez, M.E., Mariscal, M.P. (2000). Biodegradable plastics made from bean products. Industrial Crops and Products. 11: 217-225.

Shogren, R. L. (1998). In Biopolymers from Renewable Resources; Kaplan, D., ed.; Springer-Verlag: Berlin,; pp 30-46.

Suvorova, A. I.; Tyukova, I. S.; and Trufanova, E. I. (2000). Biodegradable starch-based polymeric materials. Russ. Chem. Rev. 69(5):451-459.

Thakore, I. M.; Iyer, S.; Desai, A.; Lele, A.; Devi, S. J. (1999).Morphology, thermomechanical properties, and biodegradability of low density polyethylene/starch blends Appl Polym Sci, 74, 2791.

Thiebaud, S.; Aburto, J.; Alric, I.; Borredon, E.; Bikiaris, D. Prinos, J.; Panayiotou, C. (1997).Properties of fatty-acid esters of starch and their blends with LDPE J Appl Polym Sci, 65, 705.

Van Soest, J., Kortleve, P. (1999). The influence of maltodextrins on the structure and properties of compression molded starch plastic sheets. Journal of Applied Polymer Science.74(9): 22072219.

Willet, J.L. J. (1994) Mechanical properties of LDPE/granular starch composites Appl. Polym. Sci. 541685.

Yoon, B.S. .,M.H. Suh, S.H. Cheong, J.E. Yie, S.H. Yoon, S.H. Lee. (1996) Studies on the degradable polyethylenes: Use of coated photodegradants with biopolymers J. Appl. Polym. Sci. 60 1677. 